\title{
PRESENCIA DE CRYPTOSPORIDIUM SPP. EN TERNEROS DE ESTABLECIMIENTOS LECHEROS DE LA PROVINCIA DE SANTA FE (ARGENTINA)
}

\author{
Aguirre, F.1; Ruiz, M. F. ; Allassia, M. ${ }^{2}$; \\ BAGATTIN, L. ${ }^{3}$ \& OTERO, J. L. ${ }^{4}$
}

\begin{abstract}
RESUMEN
Cryptosporidium spp. es un protozoo parásito que afecta comúnmente a bovinos. Los objetivos del presente trabajo fueron estimar la prevalencia de este microorganismo en terneros de crianza artificial en establecimientos lecheros de la provincia de Santa Fe; y estudiar la asociación entre la presencia de este parásito con la edad de los animales, con la diarrea y con diferentes condiciones productivas. Se analizaron heces de terneros de edades comprendidas entre 1 y 119 días. Se utilizó el método de concentración de ooquistes de Sheather y se empleó la coloración de Kinyoun. La prevalencia encontrada fue de 19,87\%. Los animales menores de 3 semanas de edad fueron los más afectados. Se detectó una relación estadísticamente significativa entre la presencia del parásito y la diarrea. Las diferentes prácticas agropecuarias y las medidas correctas de higiene e instalaciones acordes parecen no tener impacto en la disminución de la prevalencia de Cryptosporidium spp.

Palabras clave: Cryptosporidium, terneros, diarrea, Santa Fe.
\end{abstract}

\section{SUMMARY}

Presence of Cryptosporidium spp. in calves from dairy farms in Santa Fe province (Argentina).

Cryptosporidium sp. is a protozoan parasite that usually affects cattle. The goals of this work were: calculate the prevalence of this microorganism in artificially raised calves from eight dairy farms in Santa Fe province, and the association with some variables, like the age, diarrhea and different raising manages. We analyzed faeces from calves of 1-119 days old by oocyst concentration

1.- Laboratorio de Análisis Clínicos. Hospital de Salud Animal (HSA). Facultad de Ciencias Veterinarias (UNL) Kreder 2805. (3080) Esperanza, provincia de Santa Fe. Email: faguirre@fcv.unl.edu.ar

2.- Prácticas Hospitalarias de Grandes Animales, HSA. FCV (UNL).

3.- Cátedra de Patología Básica. FCV (UNL).

4.- Cátedra de Microbiología de los Alimentos. FCV (UNL).

Manuscrito recibido el 18 de junio de 2014 y aceptado para su publicación el 21 de octubre de 2014. 
(Sheather technique) and Kinyoun stain. The prevalence was 19,87\%. Calves under 3 weeks old were mostly affected. We detected a statistical association between the presence of the parasite and diarrhea. Farming management and hygienic facilities seemed having no effect in the decrease of Cryptosporidium spp. prevalence.

Key words: Cryptosporidium, calves, diarrhea, Santa Fe.

\section{INTRODUCCIÓN}

El género Cryptosporidium está conformado por coccidios parásitos obligados cuyas especies afectan a un gran rango de hospedadores incluyendo a mamíferos, aves, peces y anfibios. Aunque fue descripto por primera vez a principios del siglo $\mathrm{XX}$, recién en 1980 fue considerado como agente primario causante de diarrea en ganado doméstico (Tzipori et al., 1980).

Se han descrito 4 especies con capacidad de producir morbilidad y brotes de enfermedad en el ganado: C. parvum, C. andersoni, C. baileyi y C. meleagridis. La identificación específica entre ellas requiere muchas veces de criterios moleculares ya que el tamaño y forma de los oocistos es similar, lo que hace difícil, si no imposible, la diferenciación de especies basándose en morfometría a nivel del microoscopio (Fayer, 2004).

Cryptosporidium spp. posee un ciclo de vida monoxeno desarrollándose en la mucosa intestinal, incluyendo una fase de proliferación asexual, con formación de varios estadios intermedios, seguida de una etapa de proliferación sexual que finaliza con la formación de ooquistes. Dentro del enterocito posee una localización caracterís-tica denominada intracelular extracitoplasmática formando vesículas por debajo de la membrana celular (Fayer, 2004).

Cryptosporidium spp. posee características que lo diferencian de otros coccidios intestinales que afectan comúnmente a rumiantes. En primer lugar, los ooquistes son eliminados en forma esporulada, por lo que ya son infectantes para otros animales y seres humanos. Luego, poseen una alta resistencia ambiental frente a condiciones desfavorables y desinfectantes comunes, lo que les permite mantenerse viables por largos períodos de tiempo. Una vez ingeridos por el hospedador tienen un corto período de prepatencia (3 a 5 días) propagándose rápidamente en la población susceptible (Fayer et al., 1998). Resisten en forma eficaz los tratamientos con antiparasitarios, probablemente debido a su ubicación celular característica (Tzipori \& Griffith, 1998). Pueden realizar un proceso de autoinfección endógena dentro del hospedador, lo que permite la eliminación de grandes cantidades de ooquistes (hasta 108 ooquistes por gramo de materia fecal) (Current, 1985).

Cryptosporidium spp. es ampliamente reconocido como agente patógeno para bovinos, afectando principalmente a terneros jóvenes (Fayer, 2004).

Si bien la diarrea neonatal en terneros ha sido definida como un síndrome, el cual constituye un claro ejemplo de enfermedad multifactorial, en el que actúan factores relacionados con el animal, con las condiciones ambientales y con la presencia de una gran variedad de microorganismos (virus, bacterias y protozoos), Cryptosporidium spp. constituye uno de los principales agentes etiológicos involucrados (Uga et al., 2000). En la zona de estudio se han realizado trabajos en donde se observó que Cryptosporidium spp. y Rotavirus son los microor- 